\title{
Lineage tracing and resulting phenotype of haemopoietic-derived cells in the pancreas during beta cell regeneration
}

\author{
A. Chamson-Reig • E. J. Arany • D. J. Hill
}

Received: 3 March 2010 /Accepted: 4 June 2010 /Published online: 29 June 2010

(C) Springer-Verlag 2010

\begin{abstract}
Aims Transplantation of bone marrow-derived haemopoietic stem cells following streptozotocin (STZ) treatment to induce pancreatic beta cell loss in mice causes the partial regeneration of beta cell mass, with many haemopoietic cells demonstrating endothelial cell markers. This study used genetically tagged haemopoietic lineage-derived cells to determine how endogenous cells are mobilised following beta cell loss and subsequent replacement.

Methods A double transgenic mouse model, Vav-iCre; $R 26 R$-enhanced yellow fluorescent protein (YFP), was used where only haemopoietic lineage cells expressed the Vav1 gene promoter allowing expression of the YFP reporter
\end{abstract}

A. Chamson-Reig $\cdot$ E. J. Arany $\cdot$ D. J. Hill $(\bowtie)$

Lawson Health Research Institute, St Joseph's Health Care,

268 Grosvenor Street,

London, ON, Canada N6A 4V2

e-mail: david.hill@1hrionhealth.ca

D. J. Hill

Department of Physiology and Pharmacology,

The University of Western Ontario,

London, ON, Canada

E. J. Arany · D. J. Hill

Department of Medicine, The University of Western Ontario,

London, ON, Canada

D. J. Hill

Department of Paediatrics, The University of Western Ontario, London, ON, Canada

E. J. Arany

Department of Pathology, The University of Western Ontario, London, ON, Canada gene. Between postnatal days 2 and 4 mice were injected with STZ or vehicle (control) and body weight and glycaemia were monitored. Mice were killed between days 10 and 130, and the pancreases were examined by immunofluorescence microscopy.

Results YFP-expressing cells infiltrated the pancreas at all ages, being present around newly forming islets at the pancreatic ducts, and within larger islets. Small numbers of YFP-positive cells $(<5 \%)$ co-stained for the macrophage markers F4/80 or Mac1, for cytokeratin 19, or for the transcription factor pancreatic and duodenal homeobox 1 (PDX-1), but no co-localisation was seen with insulin or other endocrine hormones. Within islets approximately $30 \%$ of YFP-positive cells co-stained for the endothelial cell marker CD31, and following STZ the number of haemopoietic-derived cells, and the proportion that were CD31-positive, both significantly increased after 21 and 40 days, coincident with a partial replacement of beta cells. Conclusions Our results suggest that following beta cell loss endogenous haemopoietic-lineage cells contribute to intra-islet angiogenesis, which supports a partial recovery of beta cell mass.

Keywords Endothelial cell · Haemopoietic $\cdot$ Regeneration Vav

$\begin{array}{ll}\text { Abbreviations } \\ \text { GTT } & \text { Glucose tolerance test } \\ \text { MAFA } & \begin{array}{l}\text { v-Maf musculoaponeurotic fibrosarcoma } \\ \text { oncogene family, protein A (avian) }\end{array} \\ \text { PDX-1 } & \text { Pancreatic and duodenal homeobox 1 } \\ \text { STZ } & \text { Streptozotocin } \\ \text { YFP } & \text { Yellow fluorescent protein }\end{array}$




\section{Introduction}

Transplantation of bone marrow cells, or separated fractions of marrow progenitor cells have been shown to facilitate the reversal of diabetes in experimental animals, and newly diagnosed individuals with type 1 diabetes [1-4]. In some studies a direct trans-differentiation of bone marrow stem cells into insulin-positive beta cells has been demonstrated, either in vivo or following lineage manipulation in vitro [57], but the direct contribution of haemopoietic stem cells to a new beta cell population has generally been found to be low and inconsistent with the associated increase in insulin secretion and normalisation of blood glucose [1, 8-10].

One mechanism for beta cell regeneration would appear to result from the differentiation of marrow-derived vascular progenitors into endothelial precursor cells, present either as isolated cells that can infiltrate the islets and pancreatic ducts, or as cells that become incorporated as differentiated endothelial cells into the pancreatic microvasculature during angiogenesis [1, 11]. Angiogenesis was accompanied by an increase in endogenous beta cells by replication, or by neogenesis of new islets from the pancreatic ducts $[1,8]$. Pancreatic vascular endothelium can induce beta cell differentiation, while also providing key signals via a shared basement membrane for beta cell growth and function [12, 13]. A paracrine interplay within the islet allows a synthesis of vascular endothelial growth factor from the beta cells to contribute to endothelial cell proliferation, whereas a reciprocal production of hepatocyte growth factor by the endothelial cells promotes beta cell growth [14].

Most studies on the contribution of marrow-derived stem cells to beta cell survival or regeneration have used transplantation of cells, sometimes with a genetic tag such as green fluorescent protein, into irradiated recipient animals made diabetic through beta cell ablation with streptozotocin (STZ) or the use of diabetes-prone animals such as the NOD mouse strain $[15,16]$. As little as $1 \%$ allogeneic chimerism of repopulated marrow was able to reverse disease in the NOD mouse diabetes model [16]. However, in a pathological series of human pancreases from individuals who had previously received haemopoietic stem cell transplants from opposite sex donors, there was no evidence of colonisation of these cells within the islets [17]. The mobilisation of marrow stem cells to colonise the pancreas appears to be linked to the presence of pancreatic tissue damage, in either the endocrine or exocrine compartments [18, 19].

Wang et al. [20] showed that when adult, green fluorescent protein-tagged bone marrow cells were transplanted into neonatal mice a proportion of these cells transdifferentiated into pancreatic ductal epithelium, a source of islet neogenesis in early life. However, there is little evidence about the contribution of endogenous marrow stem cells to normal pancreatic endocrine development, or beta cell regeneration during early life. We therefore used animals producing an improved Cre recombinase under the control of Vavl promoter elements, which were crossed with transgenic mice expressing LoxP (also known as Lox) yellow fluorescent protein (YFP) to generate mice in which haemopoietic lineage cells could be tracked anatomically. The guanine nucleotide exchange factors of the Vav family catalyse the exchange of GDP for GTP and activate the Rho family of GTPases, which are linked to growth factorinduced tyrosine kinase receptor activation [21]. Rho GTPases are associated with the control of the cytoskeleton, cell migration and differentiation, including the morphogenesis of capillaries [22]. The Vavl gene is ubiquitously expressed by all haemopoietic lineage cells, and their differentiated cell progeny including $\mathrm{T}$ cells, B cells and macrophages [23, 24]. It is also expressed in progenitor cells of the testis, but not in other non-haemopoietic tissues. The related Vav2 and Vav3 genes are more widely expressed, particularly in vascular tissue [25]. We have used Vav1-Cre/YFP mice to explore haemopoietic lineage cell migration to the endocrine pancreas during early postnatal development, with or without beta cell damage, and the resulting phenotype of these cells.

\section{Methods}

Animals Mice containing a yellow fluorescent protein gene construct (B6.129X1-Gt(ROSA)26Sor tm1(EYFP)Cos/J) (R26REYFP) were obtained from Jackson Laboratories, Bar Harbor, ME, USA, and maintained as homozygotes. Vav1 promoter (HS21/45)-iCre animals generated by D. Kioussis, National Institute for Medical Research, London, UK [23] were kindly provided by W. Hazenbos, Osaka University, Japan and maintained as heterozygotes by backcrossing with $\mathrm{C} 57 \mathrm{BL} / 6$ mice. The animals were housed in temperature-controlled rooms with a $12 \mathrm{~h}$ lightdark cycle and were given food and water ad libitum.

Experimental animals were obtained by crossing R26REYFP with the Vav-iCre strain. Double transgenic offspring (Vav-iCre;R26R-EYFP) were then identified by polymerase chain reaction of genomic DNA following an ear biopsy using the following primers: iCre sequence 5'-AGA TGC CAG GAC ATC AGG AAC CTG; 5'-ATC AGC CAC ACC AGA CAC AGA GAT C and R26R-EYFP sequences oIMR0316 5'-GGA GCG GGA GAA ATG GAT ATG; oIMR0883 5'-AAA GTC GCT CTG AGT TGT TAT; oIMR4982 5'-AAG ACC GCG AAG AGT TTG TC. Litters were randomly chosen to receive either a subcutaneous injection of $35 \mathrm{mg} / \mathrm{kg}$ STZ (Sigma-Aldrich, Oakville, $\mathrm{ON}$, Canada) freshly prepared in citrate buffer $(\mathrm{pH} 4.5)$, or 
a sham injection consisting of citrate buffer $(\mathrm{pH} 4.5)$ at 2 and 4 days of age. All pups from individual litters received the same treatment regardless of genotype. Animals were regularly weighed and their blood glucose levels were measured using a glucometer (Ascencia Breeze2; Bayer Inc., Toronto, ON, Canada) after $3-5 \mathrm{~h}$ of fasting by lancing the tail vein to obtain $1 \mu \mathrm{l}$ blood. Female and male VaviCre; R26R-EYFP animals from at least three different litters for each group were killed at days 10, 21, 40, 60, 80 and 130 , the last two representing adulthood, by $\mathrm{CO}_{2}$ asphyxiation. Pancreases, spleens and livers were collected immediately after dissection and fixed for histology.

Animal procedures were performed with the approval of the Animal Ethics Committee of the University of Western Ontario, and in accordance with the guidelines of the Canadian Council on Animal Care.

Tissue preparation Tissues were fixed in $4 \%$ paraformaldehyde/PBS overnight at $4^{\circ} \mathrm{C}$. Tissues were then washed three times for 10 min each in PBS, sequentially incubated in 5\%, $10 \%$ and $15 \%$ sucrose for $1 \mathrm{~h}$ each and embedded in OCT (Tissue-Tek, VWR International, Mississauga, ON, Canada) over dry ice. Cryosections $7 \mu \mathrm{m}$ thick were placed on SuperFrost Plus glass slides (Fisher Scientific, Toronto, ON, Canada), and stored at $-80^{\circ} \mathrm{C}$ with desiccant in an airtight bag.

Immunofluorescence Sections of pancreas were used for immunofluorescence analysis using the following primary antibodies: guinea pig anti-insulin (1:500; Abcam Inc., Cambridge, MA, USA), mouse anti-insulin $(1: 10,000$; Sigma Chemical Co., St Louis, MO, USA), rabbit antiGFP (1:200; Abcam) for YFP detection, mouse anti CD31 (1:50; Hycult Biotechnology, Uden, the Netherlands), guinea pig anti-pancreatic and duodenal homeobox 1 (PDX-1) (1:1,000; kindly provided by C. Wright, University of Vanderbilt), rat anti-F4/80 (1:10; Abcam), rat antiCD11b (Mac1, 1:20; BD Biosciences, Mississauga, ON, Canada), mouse anti-vimentin (1:100; Santa Cruz Biotechnology, Santa Cruz, CA, USA), mouse anti-glucagon (1:2,000; Sigma), mouse anti-somatostatin (1:100; Santa Cruz), mouse anti-pancreatic polypeptide (1:100; Santa Cruz), goat anti-human glucose transporter 2 (GLUT2, 1:50; Santa Cruz), rabbit anti-v-maf musculoaponeurotic fibrosarcoma oncogene family, protein A (avian) (MAFA) $(1: 1,000 ;$ Abcam), rabbit anti-surfactant protein D (1:100; a kind gift from J.R. Wright, West Virginia University), and rabbit anti-Ki67 (1:200; ThermoScientific, Freemont, CA, USA). DAPI $(1: 3,000)$ was used for visualisation of nuclear DNA. Secondary antibodies used were goat AlexaFluor 488 and 555 purchased from Invitrogen Canada Inc., Burlington, ON, Canada and used at dilutions of 1:200 to 1:500. Co-staining of the sections with YFP and each of the other markers was performed to determine co-expression for each cell type. Liver and spleen sections were stained for YFP and macrophage markers cell surface glycoprotein MAC-1 alpha subunit (MAC1) and cell surface glycoprotein $\mathrm{F} 4 / 80(\mathrm{~F} 4-80)$.

Morphometric analysis Pancreas tissue sections from at least three independent litters for each sex were examined at 10,21, 40 and 130 days old. Images were processed using Image $\mathrm{J}$ software (US National Institutes of Health, Bethesda, MD, USA, http://rsb.info.nih.gov/ij/, 19972009). The number of YFP-positive cells within an islet was counted and calculated relative to the total number of cells, or to the number of beta cells in the islet. Islet and total beta cell area were measured, and the percentage of beta cells per pancreatic section was calculated to estimate the beta cell mass in the entire pancreas. The co-localisation of YFP to endothelial cells was achieved using the endothelial marker CD31. Twenty fields of view were randomly chosen per animal (containing pancreatic parenchyma and islets) and the number of cells positive for both markers relative to the total number of YFP-positive cells was calculated. Similar methodology was used to colocalise other phenotypic markers to YFP cells, using a population of 1,500 to 2,000 cells per pancreas.

Statistical analysis Results were expressed as mean values \pm SEM. Differences between groups were examined for statistical significance using two-way ANOVA, followed by Student Newman-Keuls post hoc test when interaction was present. Values of $p<0.05$ were considered statistically significant. Values for all measurements were found to be similar for male and female mice, and the data were therefore subsequently combined.

\section{Results}

Double transgenic Vav-iCre/R26R-EYFP mice were of normal birthweight $(1.57 \pm 0.04 \mathrm{~g})$ and showed comparable growth rates for each sex until 130 days, the maximum age followed, to the single transgenic strains. Animals treated with STZ showed a small but significant decrease in body weight gain with age compared with controls (Table 1). Following STZ treatment hyperglycaemia was transient and was not different from control animals at day 10. However, relative hyperglycaemia was again seen after 14 days, which persisted until 130 days and was greater in male mice than in female mice (Table 1). Glucose tolerance in control Vav-iCre animals assessed by a glucose tolerance test (GTT) was normal at 80 and 130 days (Fig. 1) of age. STZ-treated mice had fasting hyperglycaemia and were not subjected to a GTT. 
Table 1 Body weight and fasted serum glucose concentrations for male or female $\mathrm{Vav}-\mathrm{Cre}$ transgenic mice from 10 to 130 days of age, with or without treatment with STZ

\begin{tabular}{|c|c|c|c|c|c|}
\hline \multirow[t]{2}{*}{ Age (days) } & \multirow[t]{2}{*}{ Treatment } & \multicolumn{2}{|c|}{ Glucose (mmol/l) } & \multicolumn{2}{|c|}{ Body weight (g) } \\
\hline & & Male mice & Female mice & Male mice & Female mice \\
\hline \multirow[t]{2}{*}{10} & Control & $6.8 \pm 0.2$ & $6.9 \pm 0.5$ & $5.64 \pm 0.14$ & $5.54 \pm 0.19$ \\
\hline & STZ & $7.5 \pm 0.5$ & $6.8 \pm 0.3$ & $5.55 \pm 0.16$ & $5.51 \pm 0.21$ \\
\hline \multirow[t]{2}{*}{14} & Control & $6.6 \pm 0.2$ & $6.9 \pm 0.5$ & $7.64 \pm 0.23$ & $7.52 \pm 0.33$ \\
\hline & STZ & $8.2 \pm 0.5^{*}$ & $8.1 \pm 0.4^{*}$ & $7.07 \pm 0.15$ & $7.17 \pm 0.15$ \\
\hline \multirow[t]{2}{*}{21} & Control & $6.7 \pm 0.1$ & $6.9 \pm 0.2$ & $10.09 \pm 0.34$ & $10.16 \pm 0.35$ \\
\hline & STZ & $8.5 \pm 0.3^{*}$ & $8.7 \pm 0.3^{*}$ & $8.84 \pm 0.18^{*}$ & $8.71 \pm 0.21^{*}$ \\
\hline \multirow[t]{2}{*}{40} & Control & $8.2 \pm 0.4$ & $6.3 \pm 0.4$ & $21.60 \pm 0.29$ & $17.50 \pm 0.23$ \\
\hline & STZ & $19.6 \pm 1.4^{*}$ & $11.0 \pm 0.5^{*}$ & $19.35 \pm 0.41^{*}$ & $16.36 \pm 0.29 *$ \\
\hline \multirow[t]{2}{*}{60} & Control & $7.6 \pm 0.3$ & $7.4 \pm 0.4$ & $26.01 \pm 0.51$ & $19.86 \pm 0.33$ \\
\hline & STZ & $26.6 \pm 1.4^{*}$ & $13.7 \pm 1.5^{*}$ & $22.40 \pm 0.57^{*}$ & $18.00 \pm 0.55^{*}$ \\
\hline \multirow[t]{2}{*}{80} & Control & $8.6 \pm 0.2$ & $8.1 \pm 0.2$ & $29.61 \pm 0.47$ & $22.95 \pm 0.29$ \\
\hline & STZ & $23.7 \pm 2.1^{*}$ & $14.7 \pm 1.2^{*}$ & $25.86 \pm 0.59 *$ & $21.04 \pm 0.31 *$ \\
\hline \multirow[t]{2}{*}{130} & Control & $8.7 \pm 0.3$ & $7.5 \pm 0.2$ & $39.14 \pm 0.76$ & $26.81 \pm 0.56$ \\
\hline & STZ & $19.2 \pm 3.0 *$ & $13.1 \pm 2.7^{*}$ & $31.80 \pm 1.48^{*}$ & $24.17 \pm 0.57^{*}$ \\
\hline
\end{tabular}

When the spleen of $\operatorname{Vav} / Y F P$ animals was examined at day 21 splenocytes were seen to uniformly express YFP fluorescence (Fig. 2a), and a subpopulation also expressed the macrophage markers F4/80 and Mac1, demonstrating the retention of the genetic marker within differentiated progeny (Fig. 2b). The YFP-positive cells were also seen throughout the liver as endothelial cells lining the sinusoids, and within the Kupffer cells as localised using F4/80 (Fig. 2c). Haemopoietic lineage YFP-positive cells were found within the pancreas of $\operatorname{Vav} / Y F P$ mice at all ages studied up to adulthood, but showed a significant decrease in abundance with age (Table 2). YFP-expressing cells were located within the parenchyma, lining the pancreatic ductal epithelium, and around and within the islets of Langerhans (Fig. 3a, b). Haemopoietic lineage cells surrounding the ducts were small and elongated, as were those around the periphery of the islets. Of the duct-associated YFPexpressing cells, $8.6 \pm 1.2 \%$ co-stained for cytokeratin 19 on day 40 , indicating a probable trans-differentiation into a ductal phenotype (Fig. 3b-e). A similar percentage of cells co-localised YFP and cytokeratin 19 on day 21, but few

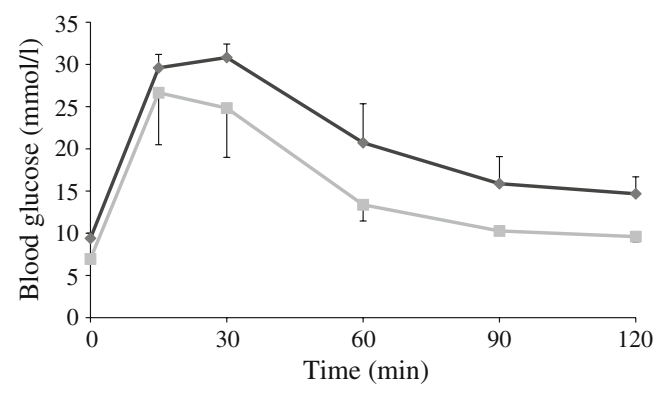

Fig. 1 Glucose values (mmol/l) during a GTT at 130 days in male (black line) or female (grey line) Vac-Cre mice. Figures represent mean values \pm SEM for six animals derived from three separate litters such cells were seen at day 130 . When small islets were seen adjacent to the ductal epithelium, probably representing neogenesis of new endocrine tissue, the haemopoietic cells were found to completely line the small islets and the adjacent ductal epithelium (Fig. 3a).

In contrast to the YFP-labelled cells associated with ducts, lineage-marked cells within the central core of the islets were large and irregularly shaped. Haemopoietic lineage cells accounted for approximately $6-8 \%$ of the islet cell population in control transgenic animals, and this did not significantly change with age (Fig. 4a). Based on calculation of the number of beta cells in the same islets this represented around a 1:8 frequency ratio of haemopoietic cells to insulin-immunoreactive beta cells. YFPexpressing cells were distributed throughout the acinar tissue with a frequency of $3.5 \%$ relative to the total number of acinar cells determined from nuclear staining with DAPI. Co-staining of Ki67 in YFP-expressing cells in either islets or acinar was rare, with only $1.3 \pm 0.2 \%$ of such cells showing Ki67 immunoreactivity within the islets.

Following treatment of mice with STZ there was no change in the number of haemopoietic lineage cells seen within the pancreas at day 10 , but the numbers of cells found in the whole pancreas, and specifically within the islets, significantly increased at days 21 and 40, and returned to control values by adulthood at day 130 (Fig. 4a, Table 2). At day 21 the ratio of haemopoietic cells to insulin-immunoreactive beta cells within the same islets increased to approximately 1:3. This might be accounted for partly by the initial loss of beta cells following STZ. However, analysis of the beta cell area per islet in STZ-treated mice (Fig. 4b) showed that this had recovered to control values by day 21 . The recovery of beta cell area after STZ treatment could not be maintained into 

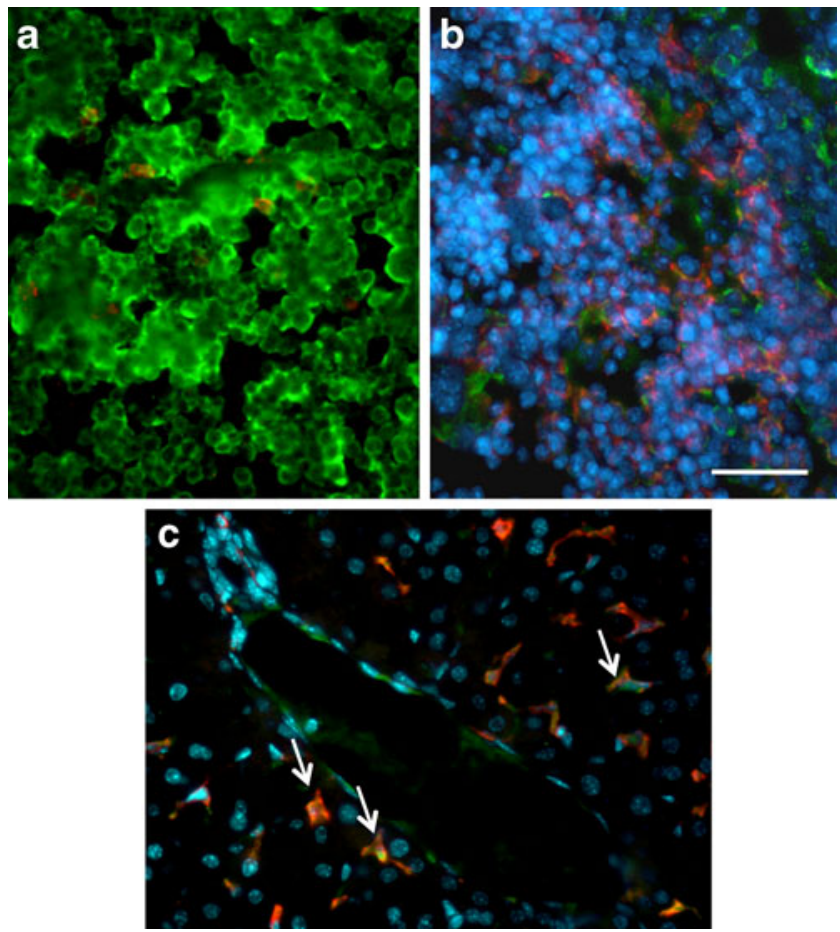

Fig. 2 Immunofluorescent localisation of YFP (green) in splenocytes from $\operatorname{Vav} / Y F P$ transgenic mice aged 21 days (a). YFP-expressing macrophage precursors were co-localised within spleen by F4-80 immunofluorescence (b, red). Within liver YFP was localised to sinusoidal epithelial cells and also co-localised with F4/80 within Kupffer cells (c, red, arrows). Nuclei are shown by DAPI stain in blue. Scale bar, $250 \mu \mathrm{m}$

adulthood and was significantly lower than in control mice by day 130 . When total beta cell mass was calculated, including all extra-islet insulin-immunoreactive cells, it was found to be decreased after STZ by around $80 \%$ at day 10 (Fig. 4c). By day 21 beta cell mass had recovered to 50 $60 \%$ of control values, but regeneration was not sustained,

Table 2 The number of YFP-positive haemopoietic lineage cells present per square micrometre of pancreas in $\mathrm{Vav}$-Cre transgenic mice between 10 to 130 days of age, with or without treatment with STZ

\begin{tabular}{lll}
\hline Age (days) & Treatment & YFP-positive cells $/ \mu \mathrm{m}^{2} \times 10^{-3}$ \\
\hline 10 & Control & $2.3 \pm 0.1$ \\
& STZ & $2.2 \pm 0.1$ \\
& Control & $1.6 \pm 0.1^{*}$ \\
40 & STZ & $4.9 \pm 0.1^{* *}$ \\
& Control & $1.2 \pm 0.1^{*}$ \\
130 & STZ & $2.4 \pm 0.1^{* *}$ \\
& Control & $1.3 \pm 0.1^{*}$ \\
& STZ & $1.1 \pm 0.1$ \\
\hline
\end{tabular}

Data from male and female animals were combined. Values represent mean $\pm \mathrm{SEM} ; n=10$ to $n=12$ animals representing three separate litters

${ }^{* *} p \leq 0.01$ vs control for same age, ${ }^{*} p \leq 0.05$ vs control day 10
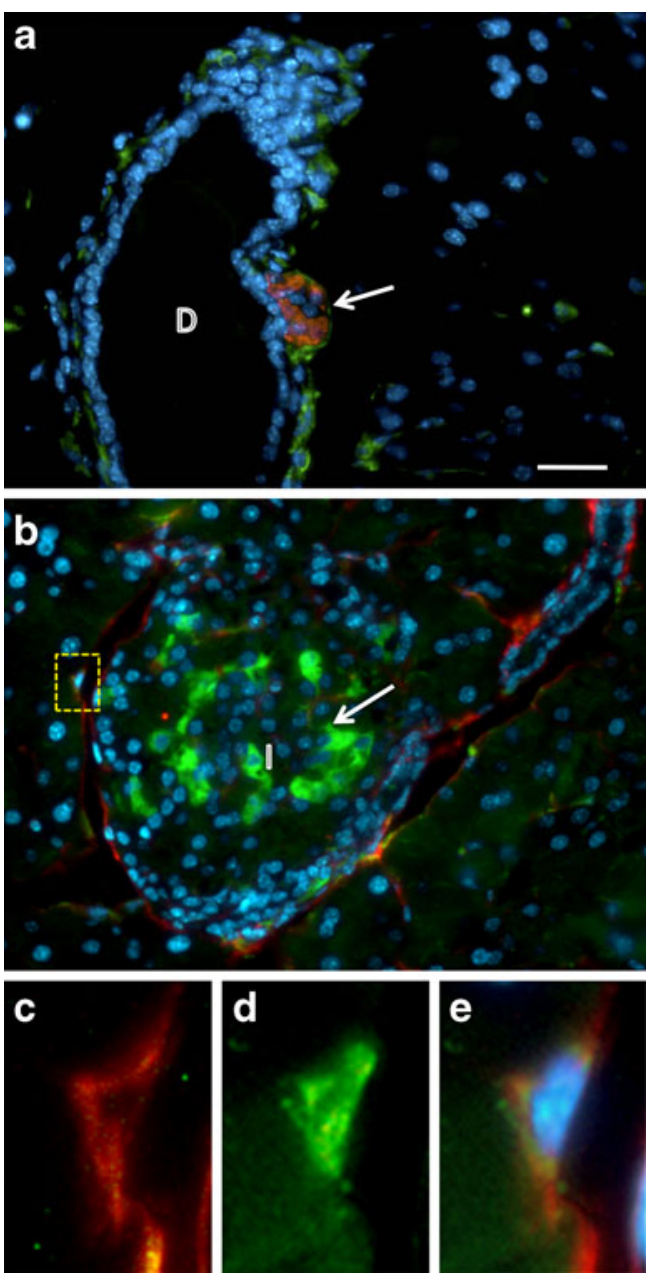

Fig. 3 a Immunofluorescent localisation of insulin (red) and YFP (green) around a pancreatic duct (D) within a Vav/YFP transgenic mouse aged 21 days. A small islet (arrow) adjacent to the ductal epithelium is shown lined by YFP-positive haemopoietic cells. b YFPpositive haemopoietic cells (green, arrow) were localised within the core of the islets (I) in mouse pancreases. The section was co-stained for cytokeratin 19 (red) to identify ductal epithelial cells. Some YFPpositive cells co-stained with cytokeratin 19 as shown within the inset in (b). This is shown at higher magnification in (c) cytokeratin, (d) YFP and (e) combined and with nuclei shown as blue by DAPI stain. Scale bars: $200 \mu \mathrm{m}$ in $\mathbf{a}$ and $\mathbf{b} ; 35 \mu \mathrm{m}$ in $\mathbf{c}-\mathbf{e}$

being $33 \%$ of control values at day 40 and only $10 \%$ of control values at day 130 . The timing of a partial recovery of beta cell mass following STZ therefore coincided with an increased number of haemopoietic cells around and within the islets.

We examined the phenotypic identity of the haemopoietic lineage cells within the pancreas, and found no co-localisation of immunoreactive insulin or glucagon (Fig. 5a, b), somatostatin or pancreatic polypeptide (not shown). However, approximately $30 \%$ of YFP-positive cells showed costaining with the endothelial cell marker, CD31 (Fig. 5c-g). Such cells were found within and surrounding the islets, as well as within the parenchyma, and were typically small and 

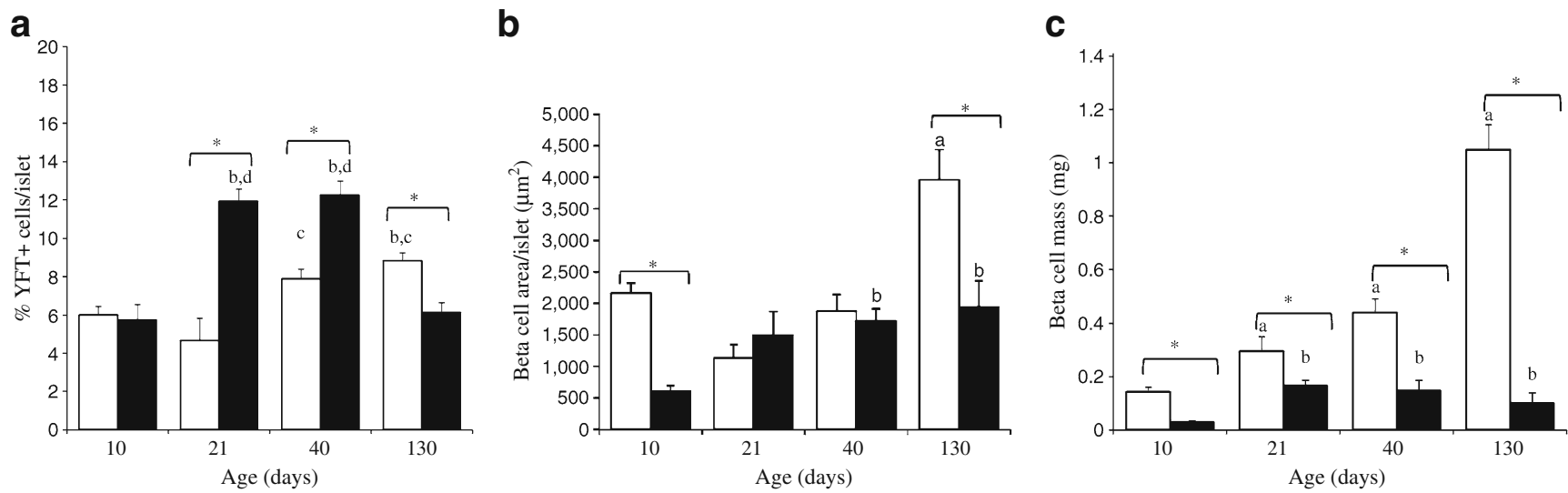

Fig. 4 a Percentage of YFP immunofluorescent cells within pancreatic islets of $V a v / Y F P$ transgenic mice following treatment with STZ (closed bars) or control (open bars) between 10 and 130 days of age. b The area of islets occupied by insulin-immunoreactive cells. c The pancreatic beta cell mass within the same animals. Figures represent mean values \pm SEM for six animals derived from three separate litters. ${ }^{*} p \leq 0.05$ for comparisons between STZ and control-treated animals at each age. ${ }^{\mathrm{a}} p<0.05$ vs all other ages within treatment, ${ }^{\mathrm{b}} p<0.05$ vs day $10,{ }^{\mathrm{c}} p<0.05$ vs day $21,{ }^{\mathrm{d}} p<0.05$ vs day 130 elongated. The percentage of CD31-positive/YFP-positive cells within the pancreas was significantly increased 21 days (control 25 $\pm 3 \%$, STZ $37 \pm 3 \%, p<0.05$ ) and 40 days (Fig. 6) after administration of STZ, but had returned to control values by day 130 ( $20 \pm 2 \%$ ). The macrophage markers F $4 / 80$ and Mac-1 were also localised in pancreas, detected by immunofluorescence. Approximately 5\% of YFP-positive
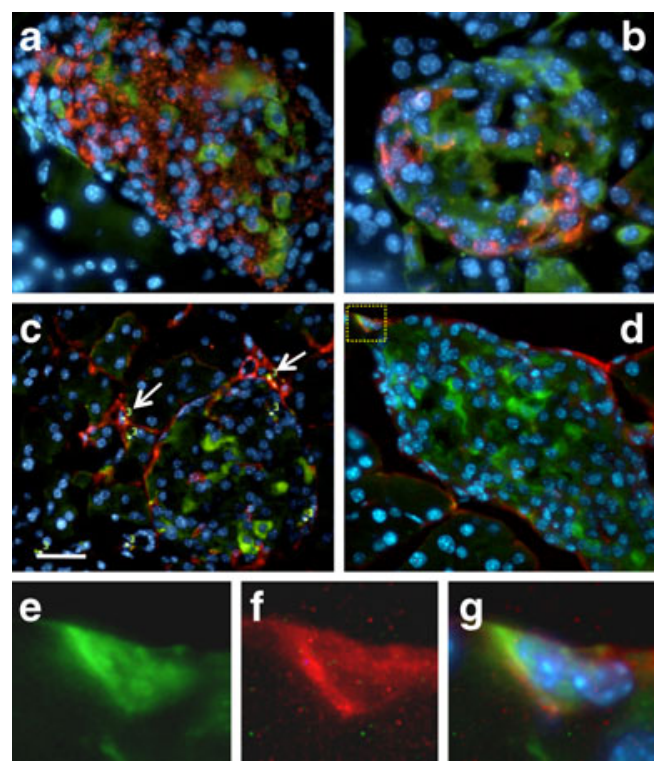

Fig. 5 Lack of immunofluorescent localisation of insulin (red) and YFP (green) (a), or glucagon (red) and YFP (green) (b) within the islets of $\mathrm{Vav} / \mathrm{YFP}$ transgenic mouse aged 40 days. Two islets $(\mathbf{c}, \mathbf{d})$ are shown with YFP (green) co-stained for CD31 (red). Some YFPexpressing cells located particularly around the periphery of the islets co-expressed CD31 (indicated ' 3 ' and examples located by arrows). One CD31-positive cell is outlined within the inset in (d) and shown at higher magnification stained for YFP alone (e), CD31 alone (f), or combined with DAPI stain to indicate nuclei (g, blue). Scale bars: $200 \mu \mathrm{m}$ for $\mathbf{a}-\mathbf{d}, 30 \mu \mathrm{m}$ in $\mathbf{e}-\mathbf{g}$ cells present in the parenchyma and around the pancreatic ducts and islets expressed these macrophage markers (Fig. 7a, b), and this percentage did not change after STZ treatment, or with age.

Large, YFP-positive cells within the islets did not costain with $\mathrm{CD} 31, \mathrm{~F} 4 / 80$ or Mac1, but $2 \%$ of these cells showed a co-localisation of PDX-1, suggesting that they may represent endocrine cell progenitors (Fig. 7c-f). This possibility is further supported by the co-localisation of both GLUT 2 and surfactant protein D within intra-islet YFP-positive cells (Fig. 8), although they did not express the transcription factor MAFA, which is a marker of beta cell differentiation, or any of the pancreatic endocrine

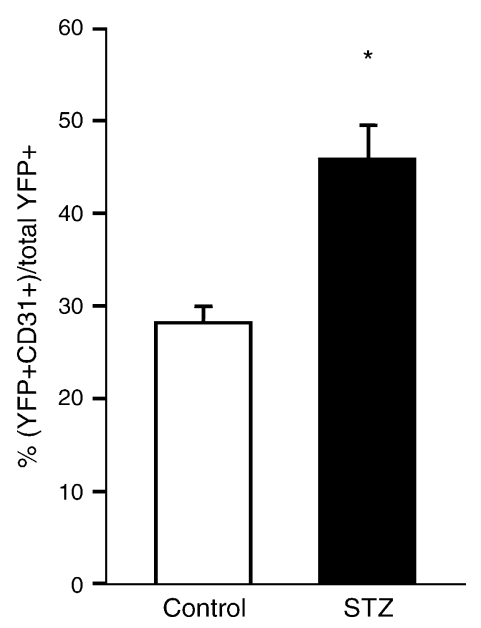

Fig. 6 Cells dual-labelled for YFP and CD31 within pancreatic islets and parenchyma were counted and expressed as a percentage of the total number of YFP-positive cells per islet in control (white bar; 1,700 YFP-positive cells) and STZ-treated (black bar; 1,800 YFPpositive cells) animals aged 40 days. Figure represents mean values \pm SEM for six animals derived from three separate litters. ${ }^{*} p<0.001$ vs control 

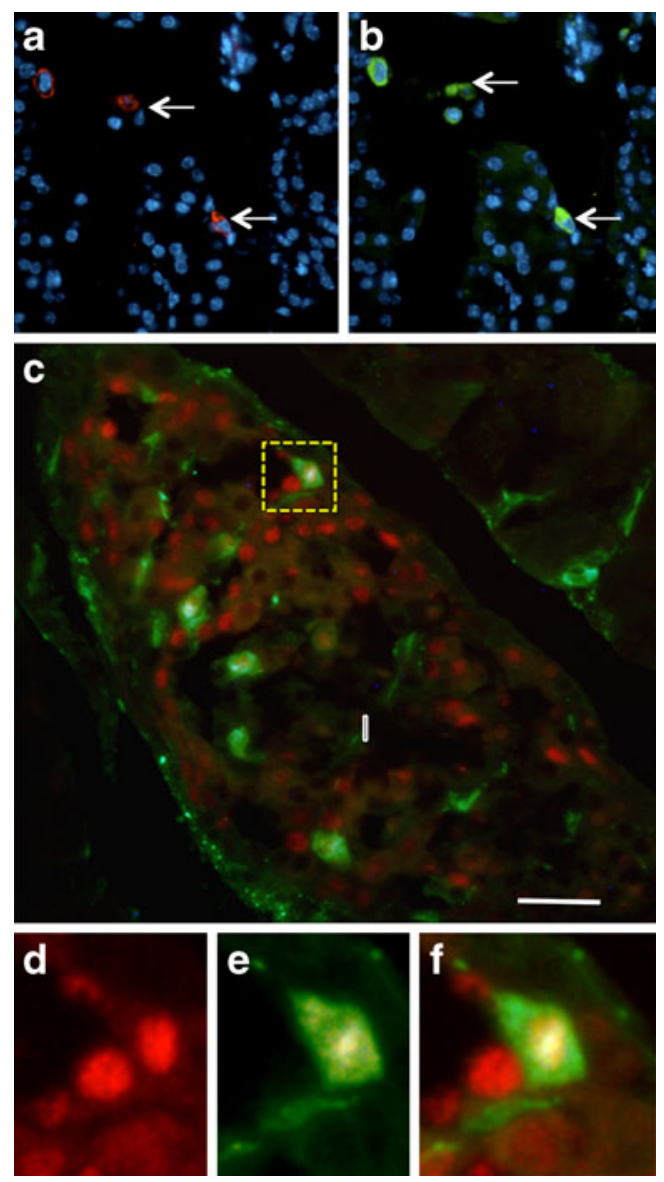

Fig. 7 Immunofluorescent co-localisation (arrows) of the macrophage marker F4/80 (a, red) and YFP (b, green) in the same pancreatic tissue section within a $\operatorname{Vav} / Y F P$ transgenic mouse aged 40 days. Nuclei are shown with DAPI stain (blue). A pancreatic islet is shown in (c) costained for YFP (green) and PDX-1 (red). Islet cells demonstrated a nuclear presence of PDX-1 with some cells also being YFP-positive. An example of a co-stained cell is shown within the inset, and at higher magnification in (d) PDX-1, (e) YFP and (f) combined. Scale bars: $200 \mu \mathrm{m}$ in $\mathbf{a}$ and $\mathbf{b}, 100 \mu \mathrm{m}$ in $\mathbf{c}$, and $30 \mu \mathrm{m}$ in $\mathbf{d}-\mathbf{f}$

hormones. The frequency of haemopoietic lineage cells that co-expressed PDX-1 did not change following STZ treatment, but did decrease with age, no such cells being apparent at 130 days. No co-localisation was found of the mesenchymal marker vimentin in the large intra-islet YFP-expressing cells, and the frequency of co-staining of such cells with cytokeratin 19 was low at all ages (day 40, 1.2 $\pm 0.8 \%$ ).

\section{Discussion}

The interpretation of the results is dependent on the specificity of expression of the YFP reporter gene to haemopoietic lineage derived cells under the control of Vavl gene promoter elements. The expression construct used was developed by Ogilvy et al. [26] and de Boer et al. [23] and includes four haemopoietic-specific sites (HS21/
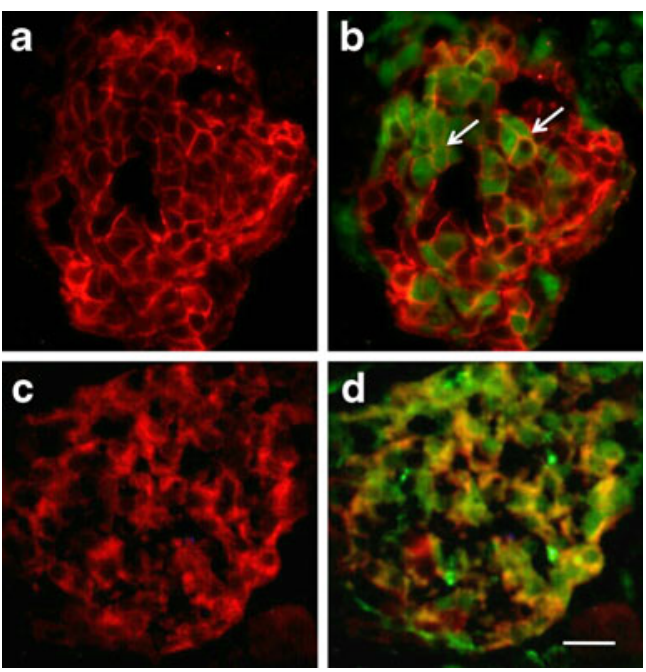

Fig. 8 Immunofluorescent localisation of GLUT2 alone (a, red) and co-localisation with YFP (b, green), and of surfactant protein D alone (c, red) and co-localisation with YFP (d, green) within pancreatic islets of a $\operatorname{Vav} / Y F P$ transgenic mouse aged 40 days. GLUT2 localisation is apparent on the plasma membranes of both beta cells within the core of the islets and of YFP-positive cells (arrows). Scale bar, $200 \mu \mathrm{m}$

45) around exon 1 of $\operatorname{Vavl}$ as well as a testis-specific promoter near exon 2. Despite the presence of the latter, expression of the reporter gene was not seen in testis and was solely restricted to haemopoietic-derived cells, including thymocytes, splenocytes, $\mathrm{T}$ and $\mathrm{B}$ cells and endothelial cells $[23,26]$. In our studies, reporter YFP gene expression was activated by $\mathrm{Vav}-\mathrm{Cre}$ in the majority of splenocytes and in the thymus. Vavl was shown to be expressed highly in cancers, including those in lung, breast and pancreatic ductal adenocarcinoma [27], but there is no evidence of expression in these tissues outside neoplasia.

As expected, haemopoietic-derived cells were present within the pancreas at all ages between 10 and 130 days, being most abundant in the neonate. No changes in abundance were seen around weaning, when an alteration in circulating immune cells might be expected to accompany transition to a solid, carbohydrate-rich diet. The haemopoietic-derived cells included the expected lineage progeny such as endothelial cells and monocytes/macrophages. However, the localisation and morphology of haemopoietic lineage cells within the pancreas were not random and were compatible with a functional interaction with endocrine cells or their progenitors. Within the pancreatic ducts of younger animals YFP-positive cells were shown to cluster around small islets in close proximity to the ductal epithelium. This is likely to represent continuing neogenesis of islets from ductal progenitors [28]. YFP-expressing cells occasionally co-stained for cytokeratin 19, indicating a probable trans-differentiation to a ductal epithelial phenotype, but none of these small, 
duct-associated YFP-expressing cells co-localised PDX-1. Wang et al. [20] showed that when adult, green fluorescent protein-tagged bone marrow cells were transplanted into neonatal mice a proportion of these trans-differentiated into pancreatic ductal epithelium. From our studies it seems unlikely that haemopoietic-derived cells directly contribute to an endocrine cell progenitor pool, at least with regard to islet neogenesis. Similarly, the majority of YFP-expressing cells associated with sites of islet neogenesis did not costain for the endothelial cell marker CD31. It is recognised that endothelial cells and their precursors can contribute to pancreatic beta cell replication and insulin release [1, 8], but our findings suggest that other haemopoietic-derived progenitors of progeny cells are also closely associated with developmental islet neogenesis in the growing mouse.

Although it was to be expected that some haemopoietic lineage cells would exhibit a phenotypic marker, CD31, of endothelial cells or their precursors, these accounted for almost $30 \%$ of haemopoietic cells within the pancreas and did not significantly change with age. Such cells were predominantly distributed within the microvasculature in and around larger islets. Approximately 5\% of pancreatic haemopoietic lineage cells expressed macrophage lineage markers, although only a proportion of macrophages resident in adult mouse pancreas were shown to express F4/80 [29]. A contribution of macrophages to normal islet development has been demonstrated and reviewed by Homo-Delarche and Drexhage [30]. Macrophages expressing F4/80 first appear in the developing mouse pancreas on day e14.5 [29], and the culture of pancreatic rudiments with macrophage colony-stimulating factor increased the number of insulin-immunoreactive cells, suggesting that an increase in macrophage number potentiated beta cell replication. In the macrophage colony-stimulating factor 1-deficient gene knockout mouse (op/op), animals develop osteopetrosis as adults, but young animals suffer from abnormal islet morphogenesis, a much reduced beta cell mass and deficiencies in beta cell replication [31]. Islet neogenesis at the pancreatic ducts was enhanced, suggesting that islets can be formed, but that the beta cell population cannot expand appropriately. There is also evidence that macrophages have a key role in islet angiogenesis through the expression of matrix metallopeptidase 9 [19].

Many haemopoietic-lineage cells were apparent as large cells within the body of established islets. These did not costain with any pancreatic endocrine hormone, or any of the other phenotypic markers used. However, a minority of such cells did co-localise the transcription factor PDX-1, a marker of pancreatic progenitors entering endocrine, exocrine and ductal lineages, and of differentiated beta cells [32]. The lack of co-staining with any endocrine hormone makes it unlikely that such cells have the capability to become functional endocrine cells, but they may represent early-stage progenitors that, nevertheless, have a trophic effect on endocrine cell development. A resident population of PDX-1-positive, but insulin-negative, cells has recently been described in mouse islets but in that study conversion to insulin-positive cells was possible [33]. Additional markers of beta cell progenitor cells include MAFA, matrix metalloproteinase 2, cytokeratin 19 and surfactant protein D [34]. Large YFP-labelled cells within the core of the islets did co-stain with GLUT2 and surfactant protein D, but not with MAFA. This suggests that the cells do exhibit some markers of a pancreatic endocrine lineage but are unable, at least in this model, to functionally mature.

Evidence of any mechanistic contribution of haemopoietic lineage cells to the regulation of beta cell mass in the pancreas was sought following its experimental depletion in the neonate using STZ. This reduced total beta cell mass by more than $80 \%$, and the area occupied by beta cells within persisting islets by approximately $70 \%$. Within the islets the fractional area occupied by insulin-positive cells had recovered fully by 21 and 40 days, but could not be sustained in adulthood. Recovery was less complete when expressed as total beta cell mass, including individual insulin-positive cells and small clusters. Hyperglycaemia occurred in mice 40 days after STZ treatment and lasting into adulthood, this being greater in males than in females. The long-term hyperglycaemia may have contributed to the reduced beta cell mass seen at 130 days, although beta cell mass did not differ with sex. We have recently reported the ontogeny of beta cell replacement in the neonatal mouse following STZ treatment using a similar regimen to this study [35]. Beta cell mass was largely replaced within 30 days, predominantly from within existing islets.

The fractional number of haemopoietic lineage cells located within islets following STZ was unchanged after 10 days, indicating no acute response to the extensive beta cell destruction. However, numbers were significantly increased at 21 and 40 days in parallel with beta cell replacement within the islets. A similar pattern was found when examining the number of haemopoietic lineage cells per unit area of whole pancreas, suggesting that trafficking was not only to the islets. The increased numbers of such cells within the pancreas was not linked to persistent hyperglycaemia because this was not apparent until 40 days after STZ. When the percentage of islet-associated YFPpositive cells demonstrating an endothelial marker was considered this was similarly increased, indicating that a greater proportion of haemopoietic-derived cells contained the endothelial cell marker during a period of beta cell replacement. The findings are consistent with the increase in beta cell number seen following the transplantation of exogenous, marrow-derived haemopoietic cells into animals treated with STZ $[1,6]$. The latter can be partially explained by the differentiation of marrow-derived endo- 
thelial precursor cells into endothelial cells as part of an angiogenic response within the pancreatic microvasculature [1, 11], accompanied by an increase in endogenous beta cell replication [1]. Our results suggest that endogenous haemopoietic lineage cells might play a similar role. However, neither the increased pancreatic presence of YFP-tagged cells, or the recovery of beta cell mass was sustainable into adulthood in this model. Pancreatic YFP-positive cells expressing macrophage markers, cytokeratin 19 or PDX-1, did not show a change in relative presence following STZ treatment, although the relatively low frequency of such cells compared with those demonstrating CD31 made quantitative sampling difficult.

In summary, using genetic tagging of haemopoietic lineage cells we have shown their presence during normal pancreatic development postnatally with at least four progeny phenotypes, endothelial cells, macrophages, epithelial cells and PDX-1-expressing cells, showing differential distributions within islets and around ducts. Following induced beta cell loss and subsequent recovery within islets, the total number of islet-associated haemopoietic lineage cells was increased and with a greater percentage demonstrating an endothelial cell marker. The results are consistent with a contribution of haemopoietic lineage endothelial precursors to an angiogenic response within the islet microvasculature following damage, which contributes to the recovery of beta cell mass.

Acknowledgements Financial support for these studies was provided by the Canadian Institutes of Health Research to D. Hill. We thank B. Strutt for her expert technical assistance.

Duality of interest The authors declare that there is no duality of interest associated with this manuscript.

\section{References}

1. Hess D, Li L, Sakano S, Hill DJ et al (2003) Bone marrow derived stem cells rescue hyperglycemia by regeneration of recipient islets. Nat Biotech 21:763-770

2. Xie Q-P, Huang H, Xu B et al (2009) Human bone marrow mesenchymal stem cells differentiate into insulin-producing cells upon micro-environmental manipulation in vitro. Differentiation 77:483-491

3. Sordi V, Piemonti L (2009) The contribution of hematopoietic stem cells to beta-cell replacement. Curr Diab Rep 9:119-124

4. Couri CE, Oliveira MC, Stracieri AB et al (2009) C-peptide levels and insulin independence following autologous nonmyeloablative hematopoietic stem cell transplantation for newly diagnosed type 1 diabetes mellitus. J Am Med Assoc 301:1573-1579

5. Ianus A, Holz GG, Theise ND, Hussain MA (2003) In vivo derivation of glucose-competent pancreatic endocrine cells from bone marrow without evidence of cell fusion. J Clin Invest $111: 843-850$

6. Zhao M, Amiel SA, Ajami S et al (2008) Amelioration of streptozotocin-induced diabetes in mice with cells derived from human marrow stromal cells. PLoS ONE 3:e2666
7. Luo L, Luo JZ, Xiong F, Abedi M, Greer D (2009) Cytokines inducing bone marrow SCA+ cells migration into pancreatic islet and conversion into insulin-positive cells in vitro. PLoS ONE 4: e4504

8. Hasegawa Y, Ogihara T, Yamada T et al (2007) Bone marrow (BM) transplantation promotes beta-cell regeneration after acute injury through BM cell mobilization. Endocrinology 148:2006-2015

9. Lechner A, Yang YG, Blacken RA et al (2004) No evidence for significant transdifferentiation of bone marrow into pancreatic beta cells in vivo. Diabetes 53:616-623

10. Taneera J, Rosengren A, Renstrom E et al (2006) Failure of transplanted bone marrow cells to adopt a pancreatic beta-cell fate. Diabetes 55:290-296

11. Mathews V, Hanson PT, Ford E et al (2004) Recruitment of bone marrow-derived endothelial cells to sites of pancreatic beta cell injury. Diabetes 53:91-98

12. Lammert E, Cleaver O, Melton D (2003) Role of endothelial cells in pancreas and liver development. Mech Dev 120:59-64

13. Nikolova G, Jabs N, Konstantinova I et al (2006) The vascular basement membrane: a niche for insulin gene expression and beta cell proliferation. Dev Cell 10:397-405

14. Johannson M, Mattsson G, Andersson A, Janson L, Carlsson P-O (2006) Islet endothelial cells and pancreatic beta-cell proliferation: studies in vitro and during pregnancy in adult rats. Endocrinology $147: 2314-2324$

15. Choi JB, Uchino H, Azuma K et al (2003) Little evidence of transdifferentiation of bone marrow derived cells into pancreatic beta cells. Diabetologia 46:1366-1374

16. Zorina TD, Subbotin VM, Bertera M et al (2003) Recovery of endogenous beta cell function in the NOD model of autoimmune diabetes. Stem Cells 21:377-388

17. Butler AE, Huang A, Rao PN et al (2007) Hematopoietic stem cells derived from adult donors are not a source of pancreatic betacells in adult non-diabetic humans. Diabetes 56:1810-1816

18. Ohtake K, Saito T, Satoh Y et al (2008) Bone marrow traffic to regenerating islets induced by streptozotocin injection and partial pancreatectomy in mice. Transplant Proc 40:449-451

19. Tessem JS, Jensen JN, Pelli $\mathrm{H}$ et al (2008) Critical roles for macrophages in islet angiogenesis and maintenance during pancreatic degeneration. Diabetes 57:1605-1617

20. Wang X, Ge S, Gonzalez I et al (2006) Formation of pancreatic duct epithelium from bone marrow during neonatal development. Stem Cells 24:307-314

21. Crespo P, Schuebel KE, Ostrom AA, Gutkind JS, Bustelo XR (1997) Phosphotyrosine-dependent activation of Rac-1 GDP/GTP exchange by the vav proto-oncogene product. Nature 385:169172

22. Hornstein I, Alcover A, Katzav S (2004) Vav proteins, masters of the world of cytoskeletal organization. Cell Signal 16:1-11

23. de Boer J, Williams A, Skavdis G et al (2003) Transgenic mice with hematopoietic and lymphoid specific expression of Cre. Eur J Immunol 33:314-325

24. Katzav S (2007) Flesh and blood: the story of Vav1, a gene that signals in hematopoietic cells but can be transforming in human malignancies. Cancer Lett 255:241-254

25. Brantley-Sieders DM, Zhuang G, Vaught D et al (2009) Host deficiency in Vav2/3 guanine nucleotide exchange factors impairs tumor growth, survival, and angiogenesis in vivo. Mol Cancer Res 7:615-623

26. Georgiades P, Ogilvy S, Duval H et al (2002) vavCre transgenic mice: a tool for mutagenesis in hematopoietic and endothelial lineages. Genesis 34:251-256

27. Lazer G, Idelchuk Y, Schapira V, Pikarsky E, Katzav S (2009) The haematopoietic specific signal transducer Vav1 is aberrantly expressed in lung cancer and plays a role in tumourigenesis. J Pathol 219:25-34 
28. Bonner-Weir S, Toschi E, Inada A et al (2004) The pancreatic ductal epithelium serves as a potential pool of progenitor cells. Pediatr Diab 2:16-23

29. Geutskens SB, Otonkoski T, Pulkkinen M-A, Drexhage HA, Leenen PJ (2005) Macrophages in the murine pancreas and their involvement in fetal endocrine development in vitro. J Leukoc Biol 78:845-852

30. Homo-Delarche F, Drexhage HA (2004) Immune cells, pancreas development, regeneration and type 1 diabetes. Trends Immunol 25:222-229

31. Banaei-Bouchareb L, Gouon-Evans V, Samara-Boustani D et al (2004) Insulin cell mass is altered in $C s f 1^{o p} / C s f 1^{o p}$ macrophagedeficient mice. J Leukoc Biol 76:359-367
32. Cerf ME (2006) Transcription factors regulating beta-cell function. Eur J Endocrinol 155:671-679

33. Szabat M, Luciani DS, Piret JM, Johnson JD (2009) Maturation of adult beta-cells revealed using a Pdx1/insulin dual-reporter lentivirus. Endocrinology 150:1627-1635

34. Aye T, Toschi E, Sharma A, Sgroi D, Bonner-Weir S (2010) Identification of markers for newly formed beta cells in the perinatal period: a time of recognized beta cell immaturity. $\mathrm{J}$ Histochem Cytochem 58:369-376

35. Cox AR, Gottheil SK, Arany EJ, Hill DJ (2010) The effects of low protein during gestation on mouse pancreatic development and beta cell regeneration. Pediatr Res 68:16-22 